The following paper posted here is not the official IEEE published version. The final published version of this paper can be found in the Proceedings of the IEEE Industry Applications Conference $\left(42^{\text {nd }}: 2007:\right.$ New Orleans, USA):pp.882-889

Copyright @ 2007 IEEE.

Personal use of this material is permitted. However, permission to reprint/republish this material for advertising or promotional purposes or for creating new collective works for resale or redistribution to servers or lists, or to reuse any copyrighted component of this work in other works must be obtained from the IEEE. 


\title{
Surface PM Machine Parameter Selection for Wide Field-Weakening Applications
}

\author{
W.L. Soong ${ }^{*}$, P.B. Reddy ${ }^{\#}$, A.M. El-Refaie ${ }^{\wedge}$ T.M. Jahns ${ }^{\#}$ and N. Ertugrul ${ }^{*}$ \\ *School of Electrical Engineering \\ University of Adelaide \\ Adelaide, Australia \\ ${ }^{\#}$ Dept. of Elect. and Comp. Eng. \\ University of Wisconsin-Madison \\ ${ }^{\wedge}$ Electrical Machines and Drives Lab \\ soong@ieee.org \\ Madison, WI, USA \\ patelr@cae.wisc.edu \\ GE Global Research Center \\ Niskayuna, NY, USA \\ elrefaie@research.ge.com
}

\begin{abstract}
Recent work on fractional-slot pitch, concentrated winding (FSCW) surface PM machines has shown that these machines can achieve a wide constant-power speed range. This paper shows that defining the allowable machine design parameter plane using the characteristic current and the peak back-emf provides useful insights into how application requirements restrict the machine parameters. The parameter plane also shows the influence of changing the parameters on the machine's current rating and magnet losses. As an example of a practical application, the parameter plane is used to study the FreedomCAR traction motor drive requirements and the characteristics of five FSCW surface PM machine designs.
\end{abstract}

Keywords: surface PM machines, field-weakening, constant power speed range, characteristic current, parameter plane

\section{INTRODUCTION}

Surface permanent magnet (PM) machines with conventional distributed windings have poor field-weakening performance due to their low stator inductance. However recent work on fractional-slot pitch, concentrated winding (FSCW) surface PM machines has shown that these machines have high values of stator leakage inductance which allows them to achieve a wide constant power speed range (CPSR) [1]. This type of machine has potential for demanding traction applications requiring wide CPSR, high power density and high efficiency. This paper examines the requirements of FSCW surface PM machines for the FreedomCAR program traction motors [2].

The paper firstly covers the optimal selection of the key surface PM machine equivalent circuit parameters using a novel parameter plane approach. This parameter plane is used to show how the FreedomCAR performance requirements constrain the allowable machine design. Earlier research work looking at the optimal selection of PM machine parameters for field-weakening performance have largely focussed on interior PM machines [3]-[5] and treated surface PM machines as simply a special case of an interior PM machine. These earlier studies showed that ideally the characteristic current should be equal to the rated current.

In this paper it will be shown that the machine parameter selection in a surface PM machine is a more complex trade-off in practice. In addition, this paper will examine the characteristics of five FSCW surface PM machine designs which were developed for the FreedomCAR requirements. It will be shown that the relative locations of the designs in the parameter plane and hence their characteristics can be roughly predicted based on three key machine design parameters : the number of turns, the magnet remanence and the airgap area.

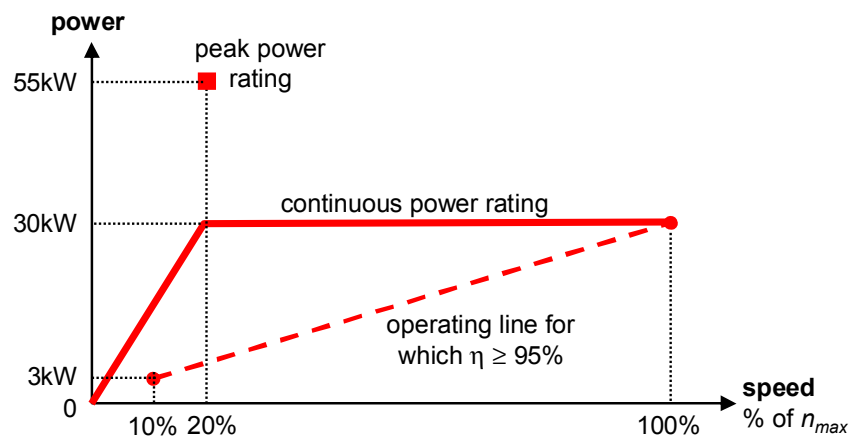

Fig. 1. FreedomCAR traction motor power requirement showing the $55 \mathrm{~kW}$ peak power and the $30 \mathrm{~kW}$ continuous output power speed range.

TABLE I. FREEDOMCAR TRACTION MOTOR REQUIREMENTS

\begin{tabular}{|l|l|l|}
\hline Parameter & Original & New \\
\hline Maximum operating speed $: n_{\max }$ & $10 \mathrm{kr} / \mathrm{min}$ & $14 \mathrm{kr} / \mathrm{min}$ \\
\hline Nominal dc link (battery) voltage $: V_{d c}$ & $325 \mathrm{~V}$ & $325 \mathrm{~V}$ \\
\hline $\begin{array}{l}\text { Peak output power at } n_{\max } \text { for } 18 \text { secs at } \\
\text { nominal voltage }\end{array}$ & $55 \mathrm{~kW}$ & $55 \mathrm{~kW}$ \\
\hline $\begin{array}{l}\text { Continuous (rated) power } 0.2 n_{\max } \text { to } \\
n_{\max } \text { at nominal voltage }\end{array}$ & $30 \mathrm{~kW}$ & $30 \mathrm{~kW}$ \\
\hline Maximum motor line current & $400 \mathrm{Arms}$ & $400 \mathrm{Arms}$ \\
\hline Maximum characteristic current $: I_{x}$ & $400 \mathrm{Arms}$ & $400 \mathrm{Arms}$ \\
\hline Peak line-to-line back-emf at $n_{\max }: E_{p}$ & $600 \mathrm{~V}$ & $600 \mathrm{~V}$ \\
\hline $\begin{array}{l}\text { Efficiency at } 20 \% \text { of rated torque from } \\
0.1 n_{\max } \text { to } n_{\max }\end{array}$ & $>93 \%$ & $>95 \%$ \\
\hline Torque pulsations - \% of peak torque & $<5 \%$ & $<5 \%$ \\
\hline
\end{tabular}

\section{FREEDOMCAR REQUIREMENTS}

The FreedomCAR program is a US D.O.E. initiative to develop advanced electric/hybrid vehicles. The FreedomCAR traction motor requirements are illustrated in Fig. 1 and TABLE I. The key motor output power requirements are 30 $\mathrm{kW}$ continuous output power over a 5:1 CPSR, and $55 \mathrm{~kW}$ peak output power at $20 \%$ of maximum speed.

TABLE I. shows both the original and an updated version of the requirements [2] which was released recently. The key differences between the two sets of requirements are an increase in the maximum operating speed $n_{\max }$ from $10 \mathrm{kr} / \mathrm{min}$ to $14 \mathrm{kr} / \mathrm{min}$ or greater, and an increase in the desired motor efficiency from $93 \%$ to $95 \%$.

Other key machine drive requirements include a maximum motor current of $400 \mathrm{~A} \mathrm{rms}$; characteristic current of less than 400 A rms; and an open-circuit back-emf limit of $600 \mathrm{~V}$ peak line-to-line at maximum speed. The last specification corresponds to the maximum dc link voltage due to the PM 
machine back-emf if control of the inverter switches is lost and the dc link is not able to absorb any regenerated power. The original requirements indicate that this peak back-emf value can be exceeded if "system requirements are met", suggesting that additional protective measures have been implemented to prevent excessive dc link voltages under this fault condition.

The above requirements assume operation with a nominal dc link voltage of $325 \mathrm{~V}$ and this value will be used for all the calculations in this paper.

\section{Surface PM Machine Parameter Plane}

This section shows how surface PM machine designs can be characterised by two equivalent circuit based parameters: the peak back-emf $E_{p}$ and the characteristic current $I_{x}$. These two parameters are used to describe the machine design space and to graphically illustrate how the requirements restrict the selection of feasible designs.

\section{A. Definition of Surface PM Machine Parameters}

Surface PM machines have two key equivalent circuit parameters: the magnet flux-linkage $\Psi_{m}$ [rms, per phase $]$ and the stator inductance $L_{s}$. In the following analysis, the effect of stator resistance, iron losses and magnetic saturation is neglected.

The rms $q$-axis voltage $V_{q}$ and $d$-axis voltage $V_{d}$ equations are given by :

$$
\begin{gathered}
V_{q}=\omega_{e} \Psi_{m}+\omega_{e} L_{s} I_{d} \\
V_{d}=-\omega_{e} L_{s} I_{q}
\end{gathered}
$$

where $\omega_{e}$ is the electrical frequency in $\mathrm{rad} / \mathrm{s}$ and $I_{d}$ and $I_{q}$ are the $d$ - and $q$-axis current components, respectively [A rms]. The stator voltage $V$ and current $I$ are defined by,

$$
\begin{gathered}
V=\sqrt{V_{d}^{2}+V_{q}^{2}} \\
I=\sqrt{I_{d}^{2}+I_{q}^{2}}
\end{gathered}
$$

The following two machine design parameters which uniquely define a surface PM machine design were chosen: the characteristic current $I_{x}$,

$$
I_{x}=\Psi_{m} / L_{s}
$$

and the peak line open-circuit voltage at maximum speed, henceforth referred to as the peak back-emf $E_{p}$,

$$
E_{p}=\sqrt{6} \omega_{e m} \Psi_{m}
$$

where $\omega_{e m}$ is the electrical frequency at the maximum operating speed. The physical significance of these two parameters is that at the maximum speed, the characteristic current is the short-circuit output current and the peak back-emf voltage is the open-circuit dc link voltage.

The voltage equations (1) and (2) can be expressed in terms of the two design parameters (5) and (6) as :

$$
\begin{gathered}
V_{q}=\frac{\omega_{e}}{\omega_{e m}} \frac{E_{p}}{\sqrt{6}}\left(1+\frac{I_{d}}{I_{x}}\right) \\
V_{d}=\frac{\omega_{e}}{\omega_{e m}} \frac{E_{p}}{\sqrt{6}}\left(-\frac{I_{q}}{I_{x}}\right)
\end{gathered}
$$

The output power $P$ can be expressed in terms of the peak back-emf using (7) and (8) as :

$$
P=m\left(V_{q} I_{q}+V_{d} I_{d}\right)=\frac{\omega_{e}}{\omega_{e m}} \frac{m E_{p}}{\sqrt{6}} I_{q}
$$

where $m$ is the number of phases. Note that the ratio of speeds is the same in $\mathrm{r} / \mathrm{min}$ or electrical $\mathrm{rad} / \mathrm{s}$ and hence $n / n_{\max }=$ $\omega_{e} / \omega_{e m}$. In (7) to (9), if the speed is defined as a ratio normalized by the maximum speed, then the equations are independent of the number of poles.

The maximum allowable machine rms phase voltage $V_{o}$ is set by the dc link voltage $V_{d c}$, where assuming linear modulation,

$$
V_{o}=\frac{V_{d c}}{\sqrt{6}}
$$

For a given dc link voltage it is possible to achieve higher phase voltages using overmodulation. However, in practice it is also desirable to have some voltage margin to allow effective current control at high speeds.

The minimum possible machine current to meet a given maximum output power rating $P_{o}$ occurs when the machine is operating at rated voltage, with unity power-factor and $100 \%$ efficiency. In this paper this value of current is called the natural current $I_{n}$ and is given by,

$$
I_{n}=\frac{P_{o}}{m V_{o}}
$$

The natural current forms a convenient benchmark for comparison purposes.

\section{B. Parameter Plane Calculations}

The peak back-emf and characteristic current parameters were chosen to define surface PM machine designs since constraints on these parameters can be readily defined based on the FreedomCAR motor drive requirements.

The peak back-emf of feasible surface PM motor designs is constrained by the $600 \mathrm{~V}$ upper limit of the requirement, see TABLE I. The lower limit is constrained by stator current limit of 400 Arms when meeting the $P_{o}=55 \mathrm{~kW}$ peak power requirement at $20 \%$ of the maximum speed, $0.2 n_{\max }$. The minimum required stator current $I$ for the peak power condition at $0.2 n_{\max }$ can be expressed using (9) as,

$$
I \geq I_{q}=\frac{5 \sqrt{6}}{m} \frac{P_{o}}{E_{p}}
$$

In addition, the minimum stator current for the $55 \mathrm{~kW}$ peak power rating must be greater than the natural current $I_{n}$, which using (10) and (11) is approximately $138 \mathrm{~A}$.

This relationship is illustrated in Fig. 2 which plots the theoretical minimum stator current rating versus peak back-emf $E_{p}$ using (12). The graph also shows the $600 \mathrm{~V}$ limitation on peak back-emf and the 400 Arms current limitation on the stator current. The 400 Arms current limitation is approximately three times the natural current. The figure shows that if the requirements are strictly followed the design range for peak back-emf lies within $571 \mathrm{~V} \leq E_{p} \leq 600 \mathrm{~V}$. This is a very narrow range of feasible designs and Fig. 2 shows that using higher peak back-emf values can significantly reduce the 


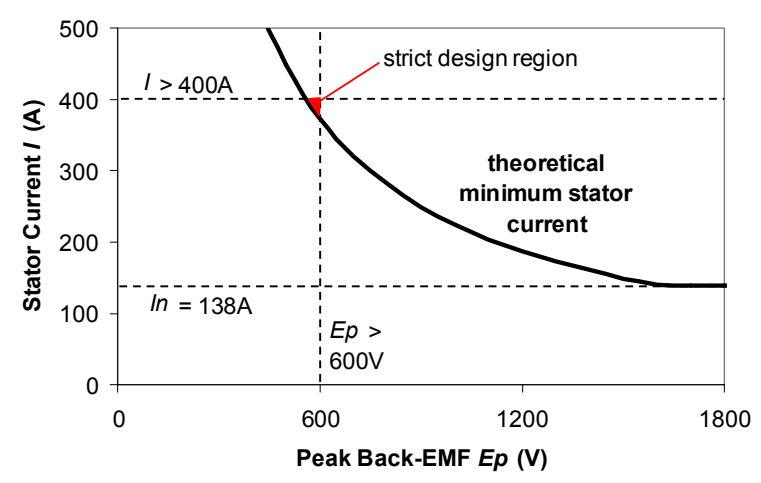

Fig. 2. Theoretical minimum stator current rating versus peak back-emf to meet $55 \mathrm{~kW}$ power requirement at $20 \%$ of maximum speed. The stator current limit, peak back-emf limit, natural current, and strict design region are shown.

inverter current rating from three times the natural current to values approaching the natural current. This needs to be considered against any increase in the inverter cost due to relaxing the peak back-emf limit [7].

The second machine parameter, the characteristic current $I_{x}$, is constrained by the $400 \mathrm{~A}$ upper limit of the requirement. The lower limit on the characteristic current is determined by the need to keep the $d$-axis voltage $V_{d}$ in (8) less than the rated voltage $V_{o}$. The worst case condition again occurs at the peak output power at $0.2 n_{\max }$, where using (8) and (12) it can be shown that

$$
V_{o} \geq V_{d}=\frac{E_{p}}{5 \sqrt{6} I_{x}} \frac{5 \sqrt{6} P_{o}}{m E_{p}}=\frac{P_{o}}{m I_{x}}
$$

From (11) it can be seen that the constraint in (13) is equivalent to the characteristic current needing to be greater than the natural current, that is, $I_{x} \geq I_{n}=138 \mathrm{~A}$.

Fig. 3 shows the proposed surface PM parameter plane which plots the peak back-emf as the $y$-axis and the characteristic current as the $x$-axis. Every point on this plane represents an alternative surface PM machine design. The figure shows the upper and lower limits on the peak back-emf and characteristic current based on the FreedomCAR requirements as horizontal or vertical lines, respectively. Each line is labelled with the constraint which produces it. The very small resulting feasible machine design space covers machines with $571 \mathrm{~V} \leq E_{p} \leq 600$ $\mathrm{V}$ and $138 \mathrm{~A} \leq I_{x} \leq 400 \mathrm{~A}$. The effect of relaxing the $600 \mathrm{~V}$ peak back-emf maximum limit to widen the design region under investigation will be explored in the next subsection.

\section{Maximum Stator Current Contour Plot}

This section explores how the maximum stator current to meet both the peak and continuous output power specification is affected by the peak back-emf and characteristic current.

At a given speed, the $q$-axis stator current was calculated from the desired output power specification shown in Fig. 1 using (9). The required corresponding $d$-axis current can be calculated using (3), (7) and (8) to satisfy the voltage constraint in (10), and the total stator current was calculated using (4).

Fig. 4 illustrates the variation of the stator current with speed in order to meet the peak and continuous power ratings for two combinations of peak back-emf and characteristic current

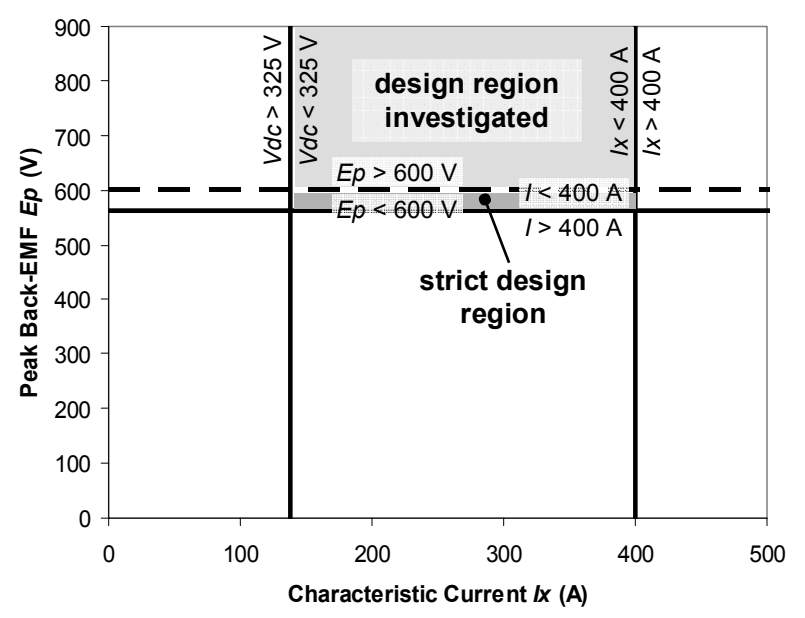

Fig. 3. Surface PM parameter plane showing the limitations defined by the FreedomCAR requirements, the small strict design area and the design area investigated after relaxing the peak back-emf specification.
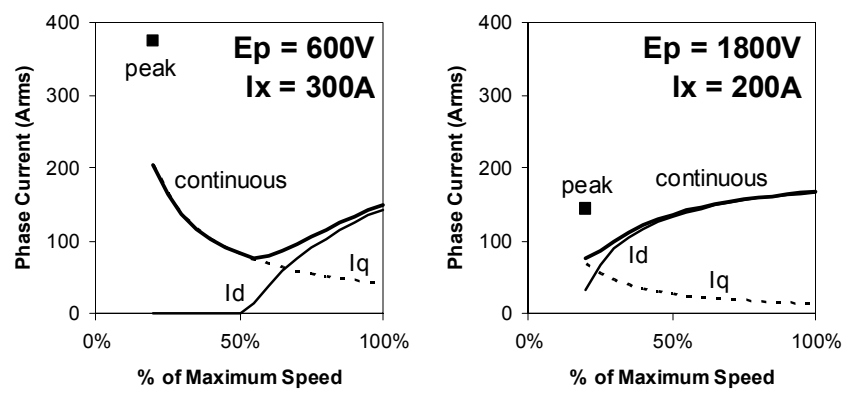

Fig. 4. Peak (square) and continuous (lines) stator current as a function of operating speed for two combinations of peak back-emf and characteristic current. The $d$ - and $q$-axis components of the continuous stator current are also shown.

values. The $q$-axis stator current $I_{q}$ is proportional to torque. As a result, it is highest at the peak power point and it falls inversely with speed in the CPSR. The $q$-axis current is also inversely proportional to peak back-emf and so increasing the peak back-emf by a factor of three reduces the $q$-axis current by a factor of three. The $d$-axis current is used for fieldweakening to meet the voltage constraint. No $d$-axis current is required until the speed is reached at which the terminal voltage reaches the voltage constraint. With high values of peak back-emf, field-weakening is required even at the peak power speed of $0.2 n_{\max }$. The total current is largest either at the minimum or maximum speeds.

Fig. 5 shows the peak and continuous stator current versus speed characteristics for a range of peak back-emf and characteristic current values. As shown in the figure, the maximum stator current generally occurs at the $55 \mathrm{~kW}$ peak power condition (shown as a square), except for designs with high peak back-emf and high characteristic current where it occurs at the maximum speed. For high values of peak backemf, the current at maximum speed approaches the characteristic current. The curves also show the natural current for the $55 \mathrm{~kW}$ condition as a dashed line which forms a lower limit for the stator current under this peak power condition.

Fig. 6 shows a contour plot of the maximum stator current on the parameter plane. As shown in Fig. 5 the maximum current is independent of the characteristic current for low values of 

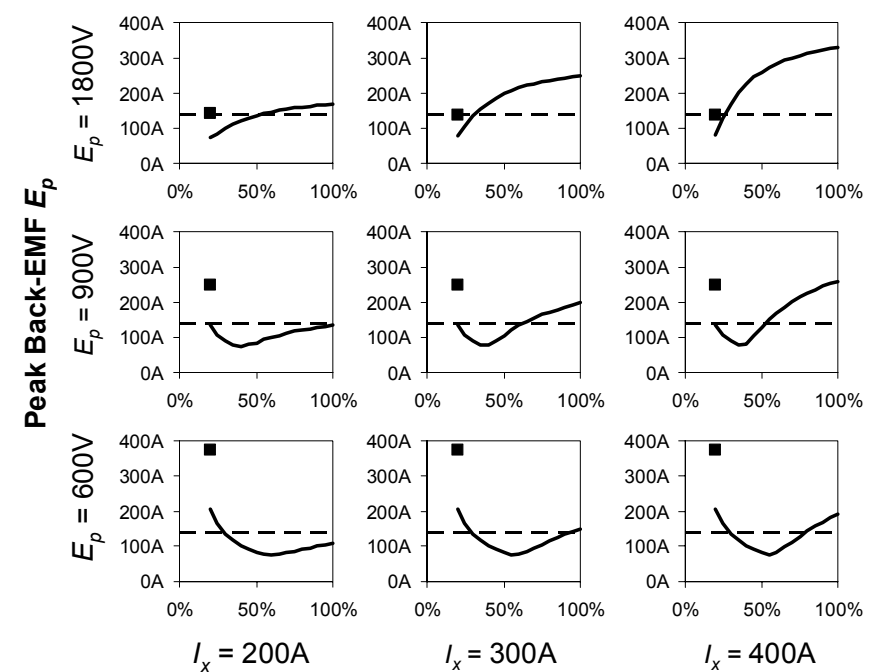

Characteristic Current $I_{x}$

Fig. 5. Peak (square) and continuous (line) stator current versus speed characteristics for $E_{p}=600 \mathrm{~V}, 900 \mathrm{~V}$ and $1800 \mathrm{~V}$, and $I_{x}=200 \mathrm{~A}, 300 \mathrm{~A}$ and $400 \mathrm{~A}$. The natural current corresponding to the $55 \mathrm{~kW}$ peak power is shown as a dashed line.

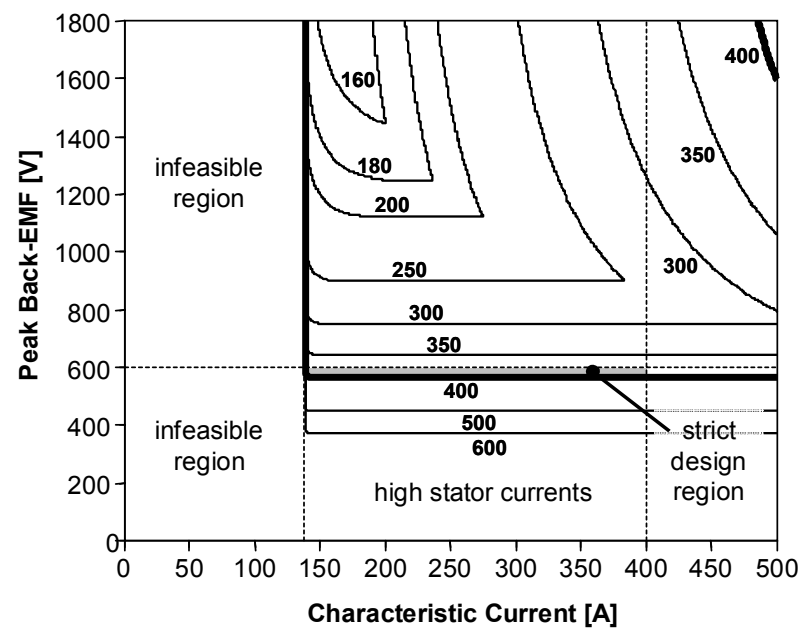

Fig. 6. Contour plot of maximum stator current on the surface PM parameter plane to meet the FreedomCAR requirements. The strict design region is shown shaded, this is bounded by the maximum peak back-emf, characteristic current and stator current requirements.

peak back-emf. As the peak back-emf increases, the maximum current falls except for high values of peak back-emf and characteristic current. The feasible machine design space is consistent with that calculated in Fig. 3. This clearly shows that it is challenging to design surface PM machines to meet the specification because of the $600 \mathrm{~V}$ peak back-emf constraint. Relaxation of this back-emf voltage limit makes it possible to significantly reduce the maximum current.

This paper is focussed on surface PM machines although interior PM machines can also be considered for the FreedomCAR traction application. In [6] it is shown the same parameter plane concept can also be applied to interior PM machines by introducing a third parameter, the saliency ratio $\left(=L_{q} / L_{d}\right)$, and using a similar analysis procedure to that described in Section III. Fig. 7 shows the resulting calculated stator current contour plot for an interior PM machine with a

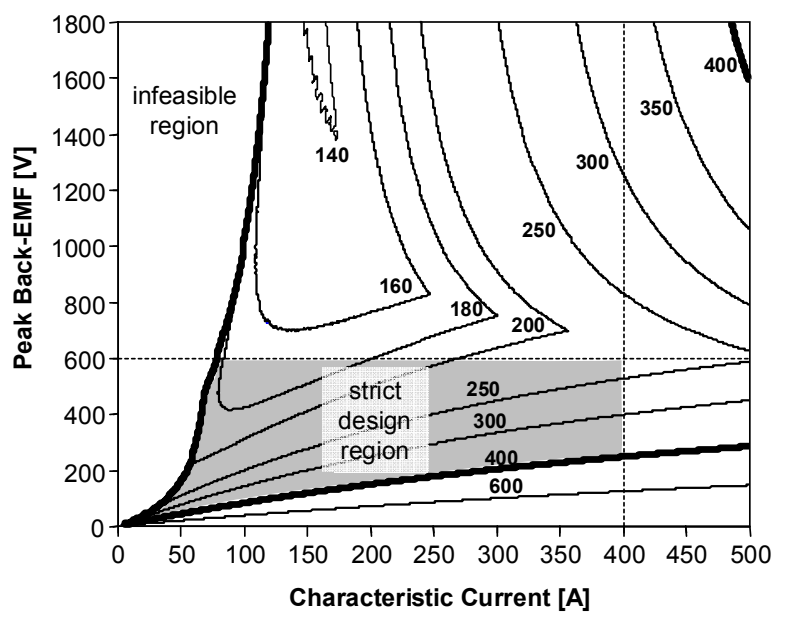

Fig. 7. Contour plot of maximum stator current for an interior PM machine with a saliency ratio of 4 to meet the FreedomCAR requirements. The strict design region is shaded. It is bounded by the maximum peak back-emf, characteristic current, and maximum stator current requirements.
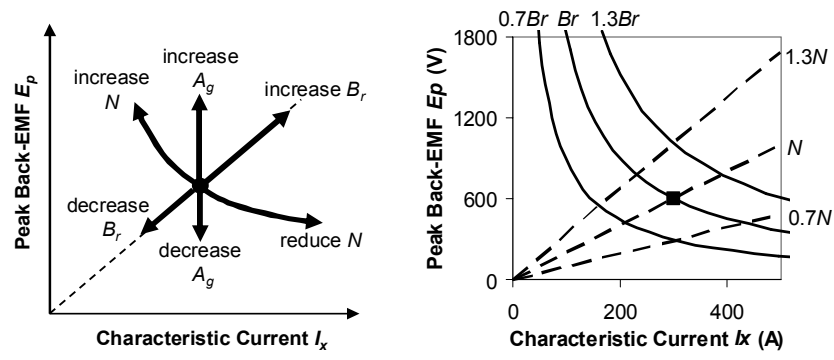

Fig. 8. The location of a particular surface PM machine design in the parameter plane can be altered by changing the magnet remanent flux density $B_{r}$, the number of turns $N$ or the airgap area $A_{g}$.

saliency ratio of 4 to meet the FreedomCAR power requirements.

In comparison to Fig. 6, Fig. 7 exhibits a considerably larger strict design region (shaded) than the surface PM machine and has much lower limits on the allowable values of characteristic current and peak back-emf. These features appear because interior PM machines have both magnet and reluctance torque which gives extra design flexibility to still meet the power requirements while maintaining a low backemf voltage. A disadvantage of the interior PM machine is that the increasing reliance on reluctance torque may degrade the machine's power density as the peak back-emf decreases [7].

\section{Effect of Changing Machine Design Parameters}

Each point on the surface PM parameter plane represents a different set of machine equivalent circuit parameters. For a given surface PM machine stator and rotor geometry, the machine's equivalent circuit parameters and, hence, its location on the parameter plane can be varied using machine design parameters such as the magnet flux density $B_{r}$, number of stator winding turns $N$ and the airgap area $A_{g}$ (see Fig. 8).

Fig. 8 illustrates how increasing $B_{r}$ increases both the peak back-emf and the characteristic current proportionally, causing the design to move along a straight line passing through the origin. In contrast, lines of constant $B_{r}$ form hyperbolas in the plane. Increasing the number of turns in the winding $N$ 


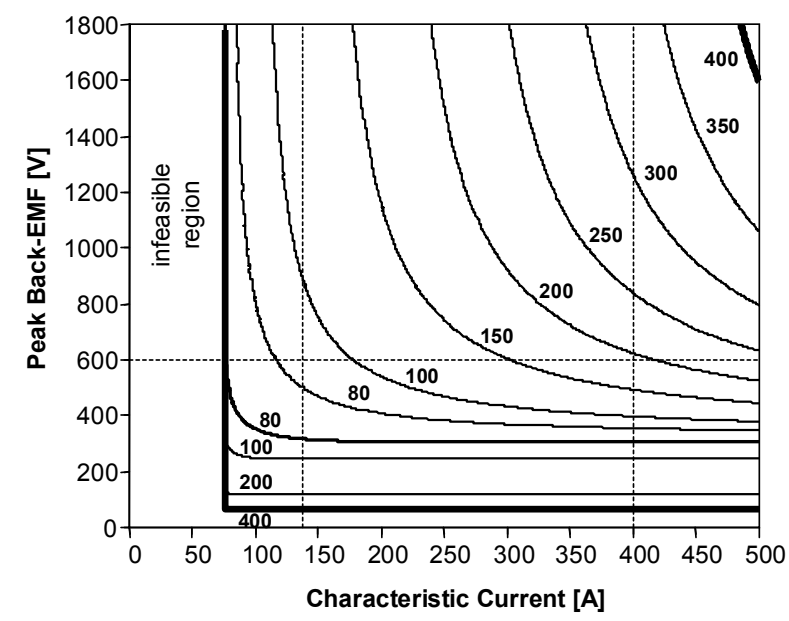

Fig. 9. Contour plot of required stator current at maximum speed to meet the $30 \mathrm{~kW}$ FreedomCAR requirements. The constraints in Fig. 3 are shown as dashed lines.

increases the peak back-emf while reducing the characteristic current, resulting in the design moving along a hyperbola in the plane; lines of constant $N$ form straight lines in the plane. Finally, increasing the airgap area $A_{g}$ (proportional to the product of airgap radius and stack length) increases the peak back-emf but does not change the characteristic current.

\section{E. Magnet Losses}

Magnet losses are an important consideration in FSCW surface PM machines. More specifically, eddy-current losses in the conductive magnets are caused by magnetic field variations produced largely by the stator winding armature reaction, with also a small contribution from the stator slotting. The magnet losses due to armature reaction are proportional to the square of the product of stator $\mathrm{mmf}$ and speed, and the stator mmf is given by the product of the number of turns and the stator current. This subsection examines how the magnet losses due to armature reaction at the maximum speed are affected by the location of the design in the parameter plane.

Fig. 9 shows a contour plot of the stator current at maximum speed to meet the $30 \mathrm{~kW}$ continuous power requirement. Note that the natural current (11) corresponding to $30 \mathrm{~kW}$ is $75 \mathrm{~A}$. Thus, from (13) the characteristic current must exceed $75 \mathrm{~A}$ and the minimum stator current must exceed $75 \mathrm{~A}$. For high values of peak back-emf this graph is similar to Fig. 6 since the maximum current in this region is determined by the machine operating characteristics at maximum speed.

As an exercise, a particular surface PM machine design is considered, and the values of $B_{r}$ and $N$ are varied to change its location in the parameter plane. Fig. 10 shows a contour plot of the square of the stator mmf at maximum speed, which is proportional to the magnet losses due to armature reaction. The stator $\mathrm{mmf}$ is the product of the stator current at maximum speed (from Fig. 9) and the number of turns (from Fig. 8). The magnet losses are normalised arbitrarily to a design with a particular combination of peak back-emf and characteristic current (shown as a square).

According to the contours in Fig. 10, the magnet losses are lowest with a peak back-emf of approximately $300 \mathrm{~V}$ and high values of characteristic current since these designs avoid the

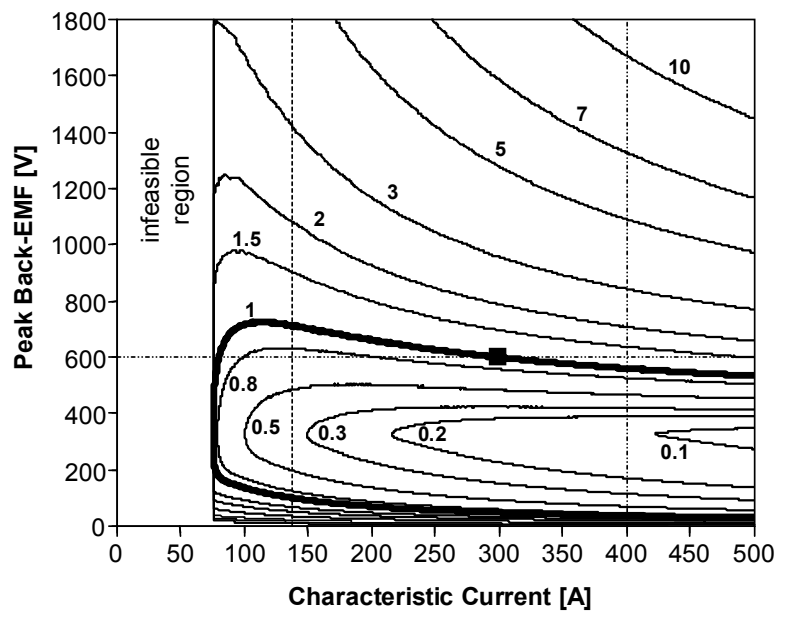

Fig. 10. Normalised "magnet losses" for a given surface PM machine design, using the square of the stator mmf at maximum speed as the surrogate variable. Data normalised to unity for a design with $E_{p}=600 \mathrm{~V}$ and $I_{x}=300 \mathrm{~A}$ (square).

need for field-weakening and, hence, require the lowest $d$-axis stator mmf. For values of peak back-emf greater than approximately $600 \mathrm{~V}$, the magnet losses increase rapidly with increases in both peak back-emf and characteristic current and hence the lowest characteristic current and peak back-emf should be used to minimize the magnet losses.

\section{Practical FSCW Surface PM Machine Designs}

The analysis in the preceding sections has explored how the selection of the surface PM machine equivalent circuit parameters is constrained by the FreedomCAR requirements. The effect of the location of the design in the parameter plane on the required stator current and magnet losses were also investigated. It has been shown that sets of equivalent circuit parameters can be found to meet the requirements, but the design space is limited. However, converting these equivalent circuit values into practical machine designs requires that several additional factors including magnetic saturation, thermal design, and other FreedomCAR requirements such as cost, size and weight must also be taken into account.

While the parameter plane cannot be used directly to design the stator and rotor geometry of a surface PM machine, it can be used to explore the effects of changing key parameters such as the magnet flux density on the performance of a given machine design. In this section, the performance of a variety of surface PM machine designs are investigated that were developed for the FreedomCAR requirements using an FSCW surface PM machine analysis tool coupled with an optimization package.

\section{A. Machine Design Process}

A closed-form analytical model [8] was used to calculate the performance of candidate FSCW surface PM machines. At the heart of this model are analytical equations for calculating the two-dimensional airgap magnetic field distribution in surface PM machines where the thickness of the airgap and magnets cannot be neglected. The effects of stator armature reaction fields, stator slotting, radial or parallel magnetization, and nonunity magnet relative permeability are taken into account, although saturation is neglected. 
TABLE II. KEY PARAMETERS FOR FIVE CANDIDATE 30 POLE, 36 SLOT FSCW SURFACE PM MACHINE DESIGNS.

\begin{tabular}{|c|c|c|c|c|c|}
\hline Parameter & A1 & A2 & A3 & P2 & P3 \\
\hline Magnet Rem. Flux Dens. $B_{r}[\mathrm{~T}]$ & 1.0 & 1.0 & 0.55 & 1.0 & 1.0 \\
\hline Magnet Mass [kg] & 2 & 2 & 5 & 2 & 2.3 \\
\hline Turns per Stator Coil $N$ & 8 & 5 & 6 & 4 & 5 \\
\hline Stator Diameter [mm] & 269 & 269 & 269 & 277 & 300 \\
\hline Air-gap Radius [mm] & 100 & 100 & 108 & 105 & 112 \\
\hline Stack Length [mm] & 64 & 68 & 86 & 70 & 65 \\
\hline Relative Airgap Area [pu] & 0.94 & 1.00 & 1.38 & 1.09 & 1.07 \\
\hline Normalized Shear Stress [pu] & 1.07 & 1.00 & 0.67 & 0.88 & 0.84 \\
\hline Inductance [ $\mu \mathrm{H}]$ & 180 & 66 & 95 & 48 & 72 \\
\hline Peak Line Back-EMF [V] & 950 & 600 & 563 & 585 & 666 \\
\hline Characteristic Current [Arms] & 146 & 263 & 201 & 312 & 228 \\
\hline Maximum Current [Arms] & 330 & 430 & 550 & 470 & 390 \\
\hline Peak Current Density [A/mm $\left.{ }^{2}\right]$ & 15.4 & 12.4 & 21.6 & 11.6 & 11.4 \\
\hline
\end{tabular}

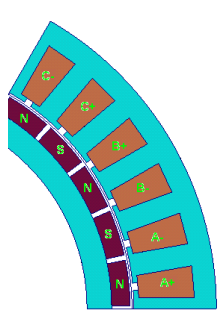

$\mathrm{A} 1 / \mathrm{A} 2$

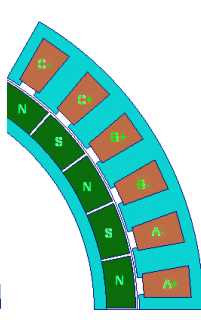

A3

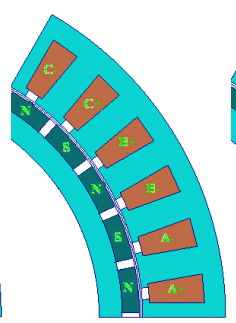

P2

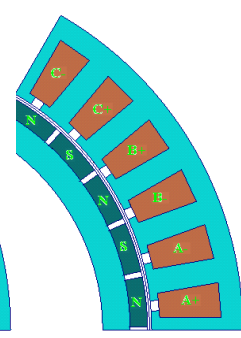

P3
Fig. 11. Cross-sections of the five 30 pole, 36 slot surface PM machine designs developed for the original FreedomCAR specification. Designs A1, A2, P2 and $\mathrm{P} 3$ are sintered magnet designs and $\mathrm{A} 3$ is a bonded magnet design.

Using the analytical model, parameters such as the back-emf and inductance can be estimated which allows the calculation of the required stator current to meet the performance requirements. The model can also calculate approximate magnet and iron losses under field-weakening conditions and, hence, predict the machine efficiency. Finite-element modeling was used to validate the analytical model results and to improve the accuracy of the magnet and iron loss estimation.

A differential evolution algorithm [9] was used for the machine optimization because it is computationally-efficient for finding global minimum solutions when dealing with large numbers of design parameters. The adopted cost function was a sum of the machine material cost and the inverter cost.

The number of slots per pole per phase (SPP) is an important choice for a fractional slot-pitch machines. A value of $2 / 5$ was selected [1] because it offers a high winding factor for good utilization of the permanent magnets, provides a large leakage reactance to produce good field-weakening characteristics, and results in low cogging torque.

The design effort focused on machines with 30 poles which have 30 poles $\times 3$ phases $\times$ SPP $=36$ slots. The high pole number was chosen to reduce the stator back-iron thickness and to keep the stator slot width to a reasonable value.

\section{B. Location of Designs in Parameter Plane}

Using the above design process, five machine designs were found which meet the original $(10 \mathrm{kr} / \mathrm{min})$ FreedomCAR output power requirements. The key parameters of these designs calculated using finite-element analysis are given in TABLE II. and Fig. 11.

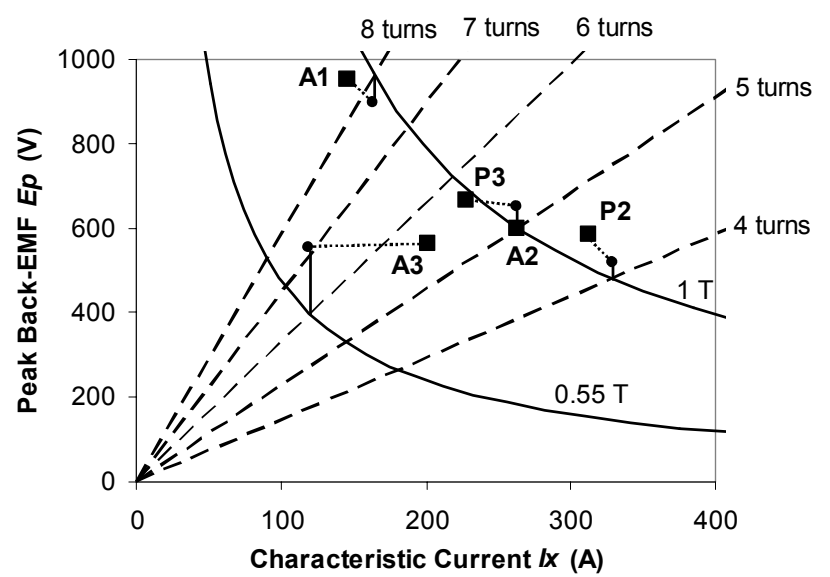

Fig. 12. Effect of changing magnet remanence (hyperbolas), number of turns (dashed lines) and effective airgap area (vertical lines) on the location of a surface PM machine design. Design A2 is used as a reference point and the estimated locations of the other designs (small circles) and their actual

locations (squares) are shown. The dotted lines show the difference between the predicted location and the actual location.

Fig. 12 explores how accurately it is possible to use the coordinates of design A2 in the parameter plane to predict the location of the four other machine designs based on the differences in magnet flux density, number of turns and airgap area. Design A2 uses 1.0 T magnets and five turns per stator coil. The figure shows the effect of changing the number of turns (dashed lines passing through origin) and the magnet remanent flux density (solid lines forming hyperbolas) in a similar fashion to Fig. 8. Design A2 has a peak back-emf of $600 \mathrm{~V}$ which is the maximum allowed by the requirements.

Design A1 was used to explore the effect of relaxing the back-emf constraint imposed for A2. It has exactly the same electromagnetic cross-section as A2 and the same magnet remanent flux density but has eight turns instead of five. The increase in the number of turns would, by itself, ideally increase the peak back-emf by $60 \%$ and reduce the characteristic current by $37 \%$. The design has a slightly shorter stack length (64 mm instead of $68 \mathrm{~mm}$ ). This gives it an airgap area (proportional to airgap radius times stack length) which is $6 \%$ less than $\mathrm{A} 2$ and a shear stress which is $7 \%$ higher as shown in TABLE II. The estimated location of A1 is shown as a small circle a short distance below the intersection of the $1 \mathrm{~T}$ and 8 turns curves. A dotted line is used to show the discrepancy between the estimated and actual locations. This discrepancy is relatively small for the A1 design.

It should be noted that, since the numbers of turns is small and constrained to integer values, fine adjustments of the peak back-emf must be performed during the design process using the stack length and other parameters to meet the performance requirements. This accounts for some of the values in Table II.

Design A3 explores the effect of using bonded magnets instead of sintered magnets that are used in the other four designs. Bonded magnets have lower remanence $(0.55 \mathrm{~T}$ versus $1 \mathrm{~T} @ 140^{\circ} \mathrm{C}$ ) but have much higher electrical resistivity than sintered magnets $(\sim 20 \mathrm{x})$. The latter point is very important in surface PM machine designs where the rotor magnets are directly exposed to high harmonic airgap fields that induce eddy currents in the magnets. The use of high- 
resistivity bonded magnets can significantly reduce the magnet losses. In addition, the lower magnet remanence allows the use of thinner stator and rotor back-iron which gives a larger airgap radius for the same stator outer diameter.

Fig. 12 shows that reducing the remanence to $0.55 \mathrm{~T}$ in design A3 substantially reduces both the characteristic current and peak back-emf. To produce equivalent circuit parameters inside the feasible region, the optimisation program increases the number of turns to six and increases the airgap area by approximately $40 \%$ with respect to design A2 by increasing both the airgap radius and stack length. This results in an airgap shear stress value which is $2 / 3^{\text {rds }}$ of that of $A 2$.

The estimated location of design A3 in Fig. 12 is significantly different than the actual location. Although the estimate of the peak back-emf is accurate, the characteristic current is substantially underestimated (120 A versus $200 \mathrm{~A}$ ). The reason for this error can be seen in Fig. 11. The estimation procedure assumes that the cross-section of the machine does not change, but this assumption is violated since the bonded magnets in A3 are much thicker than the sintered magnets in the A2 design. The thicker magnets reduce the inductance and, hence, increase the characteristic current while having only a small effect on the peak back-emf.

Designs P2 and P3 were used to explore the effect of increasing the airgap radius by increasing the stator outer diameter from $269 \mathrm{~mm}$ (A2), to $277 \mathrm{~mm}$ (P2) to $300 \mathrm{~mm}$ (P3). The aim of increasing the airgap radius was to reduce the shear stress and the resulting degree of saturation in the machine. Both designs use sintered magnets. The cross-sections of P2 and $\mathrm{P} 3$ are similar to that of A1/A2 apart from the larger stator outer diameter. Their actual locations in the parameter plane (Fig. 12) are close to their extrapolated locations based on the A2 parameters. However they both have slightly lower characteristic currents and higher peak back-emfs than estimated. Inspection of Fig. 11 indicates the lower characteristic current may be caused by an increase in the slot opening depth compared to A2.

This discussion has shown that the key machine design parameters including the number of turns, remanent flux density and airgap area are the primary factors that determine the location of the design in the parameter plane. However, secondary design parameters such as magnet thickness and slot opening depth can also exert significant influences.

\section{Stator Current Characteristics}

The peak back-emf and characteristic current parameters shown in TABLE II. were calculated using finite-element (FE) analysis. Fig. 13 shows a comparison between the calculated peak and continuous stator current for design A2 when using these parameters in (7)-(9) that ignore saturation effects, in comparison to FE-calculated results. The analytical approach using the FE-calculated parameters (solid line) gives a good correspondence with the FE results (dashed line with circles) at the $30 \mathrm{~kW}$ continuous power operation. However, closed-form analysis significantly underestimates the stator current at the peak power operating point due to substantial saturation in the machine for this operating condition. For design A2, the current error at peak power is approximately $55 \mathrm{~A}$. For the other designs the current error at peak power is generally in the range from 55 to $85 \mathrm{~A}$, except for design $\mathrm{A} 3$ where it is $150 \mathrm{~A}$.

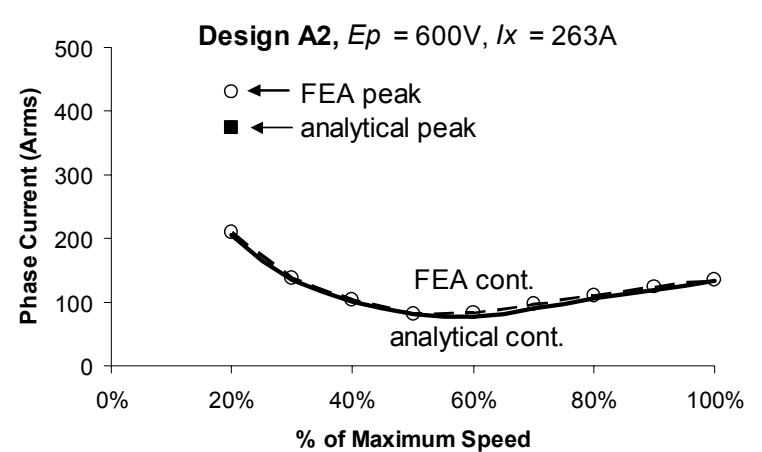

Fig. 13. Comparison of calculated peak and continuous stator current using analytical (square and solid line) and finite-element (circles and dashed line) methods for design A2.

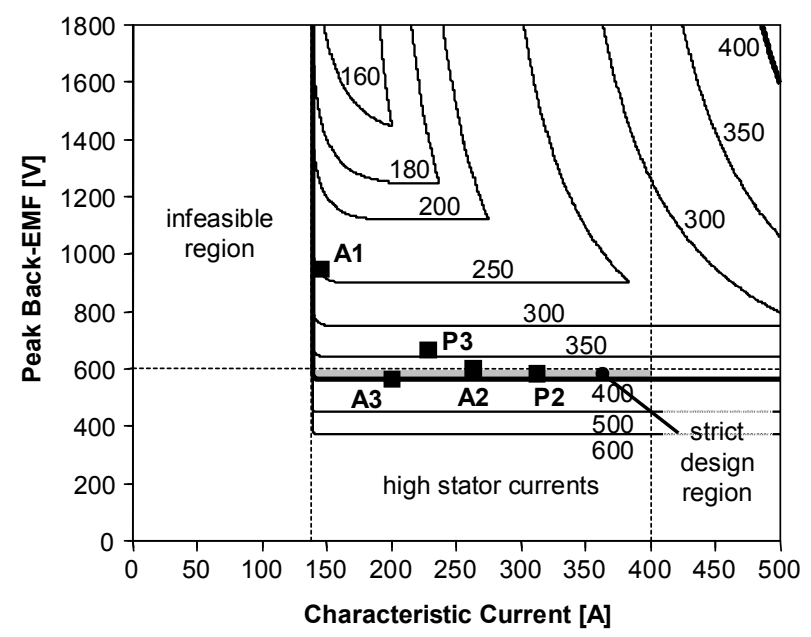

Fig. 14. Location of five 30 pole, 36 slot surface PM machines designs on a contour plot of maximum stator current.

Fig. 14 shows the locations of the five surface PM machine designs in the parameter plane superimposed on a contour plot of maximum stator current shown previously in Fig. 6. It can be seen that designs $\mathrm{A} 2, \mathrm{~A} 3$ and $\mathrm{P} 2$ all fall within the strict design region but that designs $\mathrm{P} 3$ and $\mathrm{A} 1$ exceed the $600 \mathrm{~V}$ peak back-emf specification by about $70 \mathrm{~V}$ and $350 \mathrm{~V}$, respectively. Although A2, A3 and $\mathrm{P} 2$ should theoretically have maximum stator currents below $400 \mathrm{~A}$, saturation causes the FE-predicted maximum stator currents to be in the range from $430 \mathrm{~A}$ to $550 \mathrm{~A}$. The highest maximum current is associated with design A3 which suffers very heavy saturation under the peak power operating condition.

In order to meet the 400 Arms stator current requirement, the peak back-emf for design P3 was raised to approx. $670 \mathrm{~V}$ to achieve a FE-calculated peak-power current of 390 A that meets the maximum current requirement. In design $\mathrm{A} 1$, the peak back-emf was raised even further to $950 \mathrm{~V}$ to reduce the calculated maximum stator current to $330 \mathrm{~A}$ for peak power.

In addition to minimizing the stator current, it is also desirable for thermal reasons to minimize the maximum current density in the stator winding. The stator current density is proportional to stator current and inversely proportional to the number of turns. TABLE II. shows that the stator current densities for designs A2, P2 and P3 are all in the vicinity of 12 $\mathrm{A} / \mathrm{mm}^{2}$. Design A1 has a low stator current due to its high value of peak back-emf but a high number of turns (8) that 


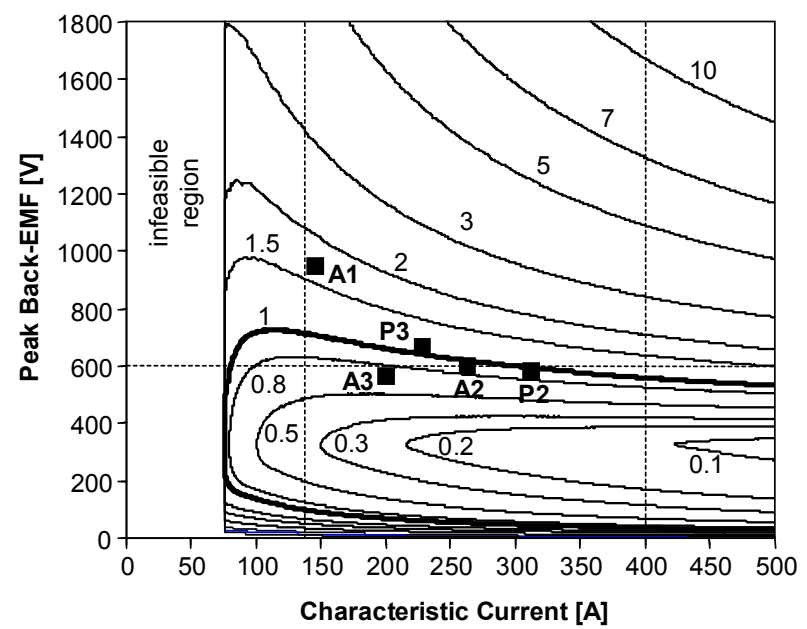

Fig. 15. Location of five 30 pole, 36 slot surface PM machines designs on the normalised magnet loss contour plot.

raises the current density to $15 \mathrm{~A} / \mathrm{mm}^{2}$. The current density of design $\mathrm{A} 3$ is particularly high $\left(22 \mathrm{~A} / \mathrm{mm}^{2}\right)$ due to its high stator current and intermediate number of turns.

Fig. 15 shows the location of the five designs on a contour plot of normalised magnet loss as shown previously in Fig. 10. The values of characteristic current for the five designs are generally less than 300 Arms, helping to minimize the magnet losses. For example, design Al has nearly the minimum allowable characteristic current which helps to offset the impact of its high back-emf on magnet losses. Note that design A3 uses bonded magnets which lower the magnet losses in this machine compared to the other designs due to the high resistivity of bonded magnets.

Among the five considered designs, design P3 is a promising candidate for meeting the original $(10 \mathrm{kr} / \mathrm{min})$ FreedomCAR power delivery and maximum current requirements, although its peak back-emf exceeds the limit by $10 \%$. Considering the remaining requirements in TABLE I., the efficiency requirement is particularly challenging due to the high electrical frequencies of these machines. Continuing investigations are under way focused on design techniques for minimizing the magnet losses and iron losses.

\section{CONCLUSions}

This paper has shown that defining the allowable surface PM machine design space using the characteristic current and the peak back-emf parameters provides useful insights into how application requirements constrain feasible designs. The influence of changing these parameters on the machine's current rating and magnet losses has also been demonstrated. The paper describes the use of the parameter plane concept to examine the ability of a number of concentrated winding surface PM machine designs to meet the FreedomCAR output power requirements. Key results of the paper include:

- A surface PM machine can be usefully categorized by its peak back-emf $E_{p}$ which is the peak line voltage at maximum speed, and its characteristic current $I_{x}$;

- The peak back-emf has an upper limit set directly by the FreedomCAR requirement and a lower limit set by the maximum stator current at peak power;
- The characteristic current has an upper limit set by the maximum current requirement and a lower limit equal to the natural current due to the rated voltage limit at peak power;

- The allowable ranges of $E_{p}$ and $I_{x}$ can be plotted in a parameter plane and used to examine how the equivalent circuit parameters affect the stator current rating of the inverter and the magnet losses;

- Relaxing the maximum limit on the back-emf voltage makes it much more practical to meet the FreedomCAR requirements using a surface PM machine;

- For a given stator and rotor geometry, changing key machine parameters such as the magnet remanent flux density, number of stator turns and airgap area allows the location of a design in the parameter plane to be optimised;

In Section IV, the analytical results developed in the preceding sections were applied to five candidate FSCW surface PM machines. The resulting comparisons illuminate the importance of understanding the interrelationships and tradeoffs between key machine parameters in order to meet demanding sets of performance requirements with FSCW surface PM machines.

\section{ACKNOWLEDGMENTS}

The financial support of the Australian Research Council Discovery grant DP0342874 for this work is gratefully acknowledged.

\section{REFERENCES}

[1] A.M. EL-Refaie and T.M. Jahns, "Optimal flux weakening in surface PM machines using fractional-slot concentrated windings," IEEE Trans. on Ind. Appl., Vol. 41, Issue 3, May/Jun. 2005, pp. 790 - 800.

[2] U.S. Department of Energy, "Development of Power Electronics and Electric Motor Technology for plug-in Hybrid Electric Vehicles, Internal Combustion Engine Hybrid Electric Vehicles and Fuel Cell Vehicle Traction Drive Applications", Funding Opportunity Announcement No. DE-PS26-06NT43001-00, Sept. 22, 2006: pp. 9-10.

[3] R.F. Schiferl and T.A. Lipo, "Power capability of salient pole permanent magnet synchronous motors in variable speed drive applications," IEEE Trans. on Ind. Appl., Vol. 26, Issue 1, Jan/Feb. 1990, pp. 115 - 123.

[4] S. Morimoto, M. Sanada and Y. Takeda, "Inverter-Driven Synchronous Motors for Constant Power," IEEE Industry Applications Society Magazine, Nov/Dec 1996, pp. 18 - 24.

[5] W.L. Soong and T.J.E. Miller, "Field-Weakening Performance of the Five Classes of Brushless Synchronous AC Motor Drives," IEE Proceedings, Electric Power Applications, Vol. 141, No. 6, Nov 1994, pp. 331-340.

[6] W.L. Soong, S.H. Han, T.M. Jahns and N. Ertugrul, "Reducing Iron Loss in Interior PM Machines under Field-Weakening Conditions", in Rec. of 2007 IEEE Ind. Appl. Soc. Ann. Meeting, New Orleans, 2007.

[7] S.H. Han, T.M. Jahns, M. Aydin, M.K. Guven, and W.L. Soong, "Impact of Maximum Back-EMF Limits on the Performance Characteristics of Interior Permanent Magnet Synchronous Machines," in Rec. of 2006 IEEE Industry Applications Society Annual Meeting, Vol. 4, Oct. 2006, pp. $1962-1969$.

[8] A.M. EL-Refaie, "High Speed Operation of Permanent Magnet Machines", Ph-D Thesis, University of Wisconsin-Madison, 2005.

[9] D. Zarko, "A systematic approach to optimized design of permanent magnet motors with reduced torque pulsations". Ph.D. Thesis, University of Wisconsin - Madison, 2004. 